\title{
Violência Sexual Intrafamiliar e Gravidez na Adolescência: Uma Leitura Bioecológica*
}

\author{
Silvia Renata Magalhães Lordello** @ \& Liana Fortunato Costa (๑ \\ Universidade de Brasília, Brasília, DF, Brasil
}

\begin{abstract}
RESUMO - Este artigo tem por objetivo investigar a vivência da gravidez adolescente decorrente de violência sexual intrafamiliar e as significações presentes nesta dinâmica peculiar. Trata-se de estudo de caso sobre uma adolescente de 15 anos, atendida em hospital público. Pelo método da inserção ecológica, as informações foram construídas a partir de entrevista semiestuturada e de registros do diário de campo, sendo a análise realizada com base na teoria bioecológica. Os resultados apontaram processos proximais que permitiram minimizar efeitos disfuncionais e colaborar no empreendimento da maternidade, diante da vivência traumática e da adversidade. Aspectos contextuais destacaram a importância da comunicação no microssistema familiar e o papel da rede de apoio na ressignificação da maternidade, incluindo-a em seu projeto de vida.
\end{abstract}

PALAVRAS-CHAVE: gravidez, violência sexual, adolescência

\section{Intrafamiliar Sexual Violence and Teenage Pregnancy: A Bioecological Reading}

\begin{abstract}
This paper aims to investigate the experience of adolescent pregnancy resulting from intrafamily sexual violence and meanings in this peculiar dynamic. This is a case study of a 15 -year-old adolescent, patient at a public hospital. Using the ecological insertion method, the information was constructed from semi-structured interview and field diary records, and the analysis was carried out based on bioecological theory. The results showed proximal processes that allowed minimizing dysfunctional effects and collaborating in the motherhood task, in face of traumatic experience and adversity. Contextual aspects highlighted the importance of communication in the family microsystem and the role of the support network in the resignification of motherhood, including it in their life project.
\end{abstract}

KEYWORDS: pregnancy, sexual violence, adolescence

A complexidade do fenômeno da violência sexual intrafamiliar traz, como um de seus principais desafios, tornar público o que é da esfera do privado. A gestação que é consequência desse tipo de violência é um desafio para a vítima e para as pessoas que fazem parte de seus múltiplos contextos.

A violência intrafamiliar se caracteriza pelo relacionamento sexual entre pessoas que são membros de uma mesma família. Trata-se de relação não necessariamente consanguínea, mas exercida pela função social de parentesco entre as pessoas inseridas no grupo. Estudos nacionais e internacionais descrevem a violência sexual intrafamiliar como uma abordagem que ocorre no ambiente da casa, com um membro de confiança da família que tem autoridade sobre a vítima, por um período contínuo de tempo (Hohendorff et al., 2015; Nunes \& Morais, 2018; Tener 2017). Esse tipo de violência é cometida, predominantemente, por pais e padrastos, e também por irmãos, tios, primos e avós (Hatchard et al., 2017).

De acordo com Gomes et al. (2014), a violência sexual intrafamiliar conta com ameaças verbais e físicas para impedir sua divulgação. Ao ser cometida por um membro

\footnotetext{
* Trabalho derivado da tese de doutorado da primeira autora, orientada pela segunda.

** E-mail: smrlordello@gmail.com

u Submetido: 09/10/2019; Revisado: 21/01/2020; Aceito: 25/03/2020.
} 
da própria família, a violência é emocionalmente mais intrusiva e tende a envolver um perverso pacto de silêncio. A violência sexual intrafamiliar promove uma intensa opressão à vítima: a criança ou adolescente teme o autor da violência e suas possíveis atitudes de vingança e retaliação, além de imaginar que será o responsável pela desintegração da família, caso o segredo seja revelado. Como os papéis estão indefinidos, as vítimas acham natural o comportamento do abusador, culpam-se e sentem-se responsáveis pelo abuso. Assim, protelam o pedido de ajuda, pensando que ninguém irá acreditar em seu relato (Baía et al., 2015; Rakovic-Felser \& Vidovic, 2016; Scoones et al., 2012; Tener, 2017). Com essa dinâmica na qual o descrédito é parte, o processo de revelação tende a constituir-se em um desafio para a vítima.

A violência de gênero, na qual está incluída a violência sexual, tem na sua origem o domínio masculino. Entende-se gênero, neste estudo, como elemento constitutivo de relações sociais baseadas nas diferenças entre os sexos e como uma forma primária de dar significado às relações de poder. $\mathrm{O}$ sistema dominação-exploração originado pela combinação da tríade patriarcado-racismo-capitalismo, esclarecido por Bandeira (2017), tem lugar privilegiado na compreensão da violência sexual intrafamiliar. Sabendo-se que o autor da violência é alguém que adotará uma visão utilitarista da confiança e do vínculo afetivo, será preciso uma situação crítica para o encorajamento do rompimento do silêncio. A dominação é tão passivamente aceita e aculturada que a mulher prefere permanecer na relação a provocar a destruição do lar, a partir de sua revelação. Para Nunes e Morais (2018), a violência sexual representa abuso de poder e não se mostra restrita ao ato sexual e configura-se em ato de violência e desejo de dominação.

Estudos destacam a importância de influências culturais, étnicas e religiosas que permeiam o significado do abuso sexual (Negriff et al., 2015; Pflugradt et al., 2018). Mães de origens culturais que aderem às normas patriarcais rígidas apresentam conflitos de valores sobre a preservação da família e tendem a enfrentar conflitos sobre a responsabilidade e podem apresentar descrédito diante da revelação do abuso. Assim, a relação mãe/filha pode se caracterizar pela presença de papéis confusos. A incredulidade pode se mostrar mais perceptível do que a cumplicidade. Há uma dificuldade de proteção e de enfrentamento da violência que pode ser observada na forma de negação e desprezo dos sinais (Baía et al., 2013; Santos \&
Dell'Aglio, 2013). Dessa forma, embora as mães de vítimas de abusos intrafamiliares sejam julgadas como coniventes e cúmplices, os estudos apontam que elas também são vítimas da violência de gênero, presente de forma transgeracional (Amazonas et al., 2009; Diniz et al., 2014).

Considerando os casos em que uma gravidez decorre da violência sexual intrafamiliar, a dinâmica gestacional é intensamente complexa, pois evidencia repulsa e ambivalências quando é revelada (Rakovic-Felser \& Vidovic, 2016). Em muitos casos, a adolescente mantém o segredo do qual se tornou refém. Há ainda que se considerar que a violência sexual cometida por indivíduo do sexo masculino (no caso deste texto o avô) é tida como mais agressiva e danosa do que seria uma violência sexual cometida por indivíduo do sexo feminino. Esta concepção foi apreendida, a partir das próprias vítimas, em pesquisa conduzida por Hatchard et al. (2017).

Quando há experiência sexual precoce e geradora de gravidez imposta, como no caso da violência sexual intrafamiliar, há uma desorganização do processo de maturação em curso, antecipando papéis para os quais a criança/adolescente ainda não está preparada. A descoberta da gestação decorrente do estupro produz efeitos nefastos e requer providências imediatas quanto aos direitos das vítimas. Os casos de gravidez decorrentes de estupro são contemplados no artigo 128 do Código Penal (Brasil, 1940) como condição excludente de culpabilidade para o aborto. Há, de acordo com notas técnicas oficiais, prioridade ao atendimento desses agravos, privilegiando a assistência imediata à vítima, o acolhimento e credibilidade ao relato, anticoncepção de emergência e a realização da interrupção legal da gestação (Brasil, 2012).

É direito dessas mulheres e adolescentes serem informadas da possibilidade de interrupção da gravidez, conforme art. 128, inciso II, do Código Penal (Brasil, 1940). Da mesma forma, devem ser esclarecidas do direito e da possibilidade de manterem a gestação até o seu término ou proceder com os mecanismos legais de doação. $\mathrm{Na}$ situação de se manter a gestação as mulheres enfrentam um duplo desafio: prepararem-se para o processo de maternar e, simultaneamente, controlar os efeitos das reedições das violências sofridas, tendo os filhos como depositários, por meio da transmissão geracional (Lordello \& Costa, 2014; Nunes \& Morais, 2018).

\section{IMPACTOS DA VIOLÊNCIA SEXUAL NA TEORIA BIOECOLÓGICA DE URIE BRONFENBRENNER}

Neste estudo, adota-se a Teoria Bioecológica do Desenvolvimento Humano (TBDH), originada no trabalho de Urie Bronfenbrenner (1979/1996) e que vem se destacando nas investigações sobre o tema por viabilizar o estudo dos fenômenos nos contextos em que ocorrem e por dar luz a processos cotidianos que se configuram em força propulsora do desenvolvimento humano (Bronfenbrenner \& Evans, 2000; Lordello \& Lopes de Oliveira, 2012). A gravidez decorrente de violência sexual traz inúmeros contextos de pertencimento da adolescente que terá sua 
história analisada a seguir e que se mostram fundamentais para a compreensão de seus processos proximais, conforme apontam outros estudos nacionais realizados sobre a temática (Lordello \& Costa, 2014; Nunes \& Morais, 2018).

Bronfenbrenner (1979/1996) postulou sua teoria sobre desenvolvimento humano segundo uma construção sistêmica. É preciso deixar claro que a teoria passou por três fases de aprimoramento por seu autor e o presente estudo apresentará fidelização ao terceiro período da teoria, o qual se considera o momento de maior maturidade teórica com a formulação do modelo Processo, Pessoa, Contexto e Tempo (PPCT). Nessa fase mais madura, a abordagem bioecológica dá centralidade aos processos proximais, considerando-os como atividades conjuntas com pessoas, objetos e símbolos, além de oferecer detalhamentos dos conceitos de cronossistema e das características da pessoa (Rosa \& Tudge, 2017; Tudge, 2016).

A TBDH mantém os conceitos de contextos nominados como microssistema, mesossistema, exossistema e macrossistema, que expressam os ambientes que a pessoa em desenvolvimento está inserida, de um nível mais imediato e direto até o mais abrangente, envolvendo ideologias, valores, crenças, presentes na cultura. A gestação decorrente de violência revela inserção indiscutível em todos os contextos e o que é fundamental para um entendimento mais complexo do fenômeno a ser analisado.

O conceito de processo proximal figura como principal mecanismo de desenvolvimento, segundo Bronfenbrenner (1999). Os processos vivenciados no ambiente imediato são denominados processos proximais e demandam cinco características: engajamento em uma atividade; interações recíprocas e bidirecionais; interação em base regular, por períodos estendidos de tempo; atividades progressivamente mais complexas e presença de objetos e símbolos que estimulem atenção, exploração, manipulação e imaginação da pessoa em desenvolvimento. Os processos proximais variam em função da pessoa e dos contextos. Portanto, a forma, a força, o conteúdo e a direção dos processos proximais não podem ser considerados estáticos ou determinantes (Bronfenbrenner \& Evans, 2000). Bronfenbrenner (1994) descreveu os processos proximais como eficazes na aquisição de competências ou na diminuição de disfunções. Entretanto, os conceitos de competência e disfunção não são compreendidos por si só, são definidos pelas realidades peculiares às quais se aplicam (Bronfenbrenner \& Evans, 2000; Bronfenbrenner, 2011; Rosa \& Tudge, 2017).

Nesse estudo, os processos proximais envolvidos na vivência de uma gravidez de uma adolescente, decorrente de estupro perpetrado por seu avô, poderiam associar-se imediatamente à disfunção. Mas a forma como a adolescente vai vivenciar seus processos cotidianos nos microssistemas nos quais está inserida pode trazer grande relativismo à interpretação desses efeitos sobre seu desenvolvimento. Especificamente para esse estudo, elegeu-se um conjunto de processos cotidianos estabelecidos pela adolescente grávida como objeto de análise, bem como as relações interpessoais presentes cotidianamente no contexto familiar e no hospital. O resultado do desenvolvimento psicossocial, também recomendado por Coscioni et al. (2018), para um melhor delineamento do estudo, foi a inclusão da maternidade no projeto de vida, de forma a observar estratégias e sentimentos que se construíram com vistas à criação do vínculo e da maternagem requeridas após o nascimento da criança.

Com relação à pessoa, Bronfenbrenner (2011) propõe que sejam analisadas as características, as quais nomina como: de forças (geradoras ou disruptivas), de recursos (biopsicológicos) e de demandas (causam reações favoráveis ou desfavoráveis). Estas podem ser determinadas pela herança ou construídas na interação com o ambiente e também podem ser resultado ou moderadoras dos processos proximais. O tempo, quarto elemento da teoria do PPCT, tem sua importância resgatada por Bronfenbrenner (1999), que defende o cronossistema como mais um nível de contexto de desenvolvimento. O tempo permite a análise de mudanças e permanências que ocorrem ao longo do ciclo vital.

No Brasil, são raras as pesquisas que convergem temas que unem gestação pós-estupro e a visão complexa proposta pela TDBH (Lordello \& Costa, 2014; Nunes \& Morais, 2018). Tais estudos têm como principal relevância revelar aspectos idiossincráticos dessas vivências traumáticas e descrever processos proximais possíveis de serem estabelecidos em microssistemas nos quais essa população está inserida. Como toda pesquisa bioecológica, a intenção é atuar no panorama político e social, ao subsidiar políticas públicas e acrescentar conhecimento científico aplicável às intervenções que já são desenvolvidas nos serviços públicos, como hospitais, órgãos de assistência social e delegacias especializadas, que oferecem programas de atendimento às vítimas de violência. Após a Lei 12.015/2009 (Brasil, 2009), que passou a considerar o estupro não mais restrito à conjunção carnal, mas incluiu os atos libidinosos, passou a ser ainda mais importante entender as diferentes situações que compõem esse espectro (Lima \& Deslandes, 2014), para que o trabalho em rede se torne mais claro e eficiente em cada situação de violência mencionada, evitando revitimizações e iatrogenias com um público já tão violado em seus direitos.

Diante desse panorama teórico- metodológico, o presente estudo visa a investigar aspectos presentes na vivência gravídica de uma adolescente de 15 anos cuja gestação decorreu de estupro, tencionando analisar as significações presentes nesta dinâmica peculiar à luz da abordagem bioecológica do desenvolvimento humano. 


\section{MÉTODO}

\section{Tipo de Estudo}

Realizou-se um estudo de caso único (Stake, 1995) com adolescente de 15 anos, cuja gravidez foi decorrente de violência sexual intrafamiliar e que manteve a gestação até seu término. A escolha pelo Estudo de Caso Único se deveu à sua adequação a casos raros e reveladores, cujas peculiaridades dificultam estudos comparativos. A decisão metodológica se justificou por se tratar de uma adolescente cuja gravidez decorre de estupro perpetrado por familiar, em situação de violência sexual intrafamiliar por longo tempo, cuja revelação se deu em decorrência da gravidez. Isso retardou a procura ao serviço, o que fez com que ultrapassasse o tempo gestacional requerido para o direito à interrupção legal. Elegeu-se o caso como emblemático, por concentrar temáticas pouco exploradas na literatura como gestação pós-estupro no período desenvolvimental peculiar da adolescência e cuja violência sexual se dá de maneira intrafamiliar, o que traz uma dinâmica específica e impactos em todos os vínculos familiares.

\section{Contexto da Pesquisa}

A presente pesquisa foi realizada em um programa de atendimento a vítimas de violência, constituindo-se em serviço sistematizado oferecido pela saúde pública, sendo que o espaço físico ocupado foi em um hospital público de referência local. O programa funcionava de segunda a sextafeira em horário comercial e atendia pessoas que buscavam o serviço (livre demanda) e encaminhamentos da rede.

O protocolo era iniciado por um acolhimento feito por qualquer profissional que integrava o programa, como psicólogo, assistente social e enfermeiro, acompanhado da marcação de consultas com especialidades médicas ou especialidades da equipe. Os familiares também eram convidados a participar de todo o processo e eram inseridos nas consultas e sessões de acompanhamento. Após a avaliação do caso, grupos terapêuticos, de apoio e sessões terapêuticas individuais também eram oferecidas, respeitando-se as atividades que estivessem vigorando no momento da chegada do paciente. Em caso de estupro tendo a gestação como consequência, o encaminhamento à equipe que atuava especificamente com a interrupção legal da gestação era realizado. Ali seriam realizados exames, consultas e acompanhamento interdisciplinar até a decisão ou procedimento. Fazia parte da dinâmica do programa, cuidado integral às vítimas, realizando-se o follow up dos pacientes, busca ativa e articulação com a rede de atenção para encaminhamentos e monitoramento das pessoas atendidas no serviço.

\section{Participante}

Amanda (nome fictício) é uma jovem de 15 anos que chegou ao serviço com encaminhamento da delegacia especializada onde a mãe fez a denúncia. Havia a suspeita de gravidez após episódio de abuso sexual intrafamiliar, perpetrado por seu avô materno que residia com a família. Amanda realizou atendimentos individuais e em grupo no serviço. A adolescente foi acompanhada durante toda a gestação, uma vez que o procedimento de interrupção legal não mais se aplicava em virtude de seu tempo gestacional ter ultrapassado o limite prescrito e não optou por encaminhar para a adoção. Após a decisão de que a gravidez fosse a termo, passou a frequentar grupo com outras mães na mesma situação.

\section{Instrumentos}

Entrevista com Roteiro Semiestruturado. A entrevista foi realizada com a adolescente em uma sala do hospital, com duração de uma hora, e meia e teve por objetivo abordar a relação de Amanda com os microssistemas nos quais estava inserida e investigar aspectos emocionais relacionados à vivência emocional que ela se dispusesse a revelar. $\mathrm{O}$ roteiro incluiu questões como sua trajetória até a chegada ao programa de atendimento às vítimas de violência, a reação dela e da família à descoberta da gravidez, como se sentia por estar grávida nessa situação, como foi sua acolhida por grupos e ambientes aos quais pertencia, como gostaria de ser ajudada, como se via no futuro, que planos pessoais e profissionais, e para a criação de seu bebê, apresentava e que outras informações gostaria de compartilhar a respeito de sua experiência.

Diário de Campo. O diário de campo reuniu informações em dois tipos de registros. O primeiro deles versava sobre a impressão do pesquisador em sua inserção no serviço, no acompanhamento das atividades rotineiras. O diário foi um instrumento essencial para obter dados sobre a presença sistemática do pesquisador no serviço por um ano, com duas visitas semanais de quatro horas, em turnos alternados e posteriormente, engajamento na condução dos grupos e consultas do serviço.

A segunda categoria de registros foi sobre a paciente em questão, Amanda, em todas as atividades que participou no serviço de atendimento às vítimas de violência. Esses registros incluíram as três sessões de grupo, nas quais ela esteve presente e duas consultas individuais, conduzidas pela psicóloga do serviço. O grupo era oferecido pelo serviço às mães que tiveram seus filhos decorrentes de estupro e tratava de conteúdos relacionados à vivência da gravidez nessa condição, aspectos da maternidade, rejeição e aceitação, vínculo e propostas educativas para a criança. As consultas 
individuais eram de acompanhamento sobre sua decisão sobre ter o bebê, os impactos sobre ela e os desdobramentos que o serviço de atendimento poderia representar no apoio que ela gostaria de obter sobre esse desfecho. De acordo com Morais et al. (2016), esse instrumento demanda uso sistemático do início ao fim da investigação e deve contemplar a redação das informações sobre a pessoa, o processo, o contexto e o tempo, relacionadas ao objeto de estudo.

\section{Procedimento}

\section{Coleta de Dados}

O primeiro momento de acesso ao campo foi a articulação com o programa de atendimento a vítimas de violência, que funcionava no hospital público. $O$ projeto de pesquisa foi apresentado à diretoria do hospital e ao Comitê de Ética do Instituto de Humanidades da Universidade de Brasília, obtendo autorização por meio do protocolo 02/03.

Houve autorização para acompanhar semanalmente os atendimentos e assim se deu a inserção da pesquisadora, que passou a atuar nas rotinas presentes no serviço. Dessa forma, houve um período de cerca de um ano de familiarização da pesquisadora com o contexto da pesquisa. Posteriormente, a pesquisadora passou a conduzir, junto com a equipe do hospital, atendimentos individuais e grupais de grávidas e puérperas cuja gestação tenha sido decorrente de violência sexual e, a partir dessa experiência, foi possível elaborar o roteiro de entrevista utilizado no trabalho.

Após esse período de integração, as pacientes que se cadastraram no programa de atendimento às vítimas eram esclarecidas sobre a proposta da pesquisa e convidadas às sessões grupais. Esse convite ao grupo só ocorria após a decisão por levar adiante a gravidez, evitando qualquer interferência, indução ou risco à autonomia para decidir. Amanda e sua mãe procuraram o programa nesse período e foram convidadas a participar. Após consentimento da mãe e assentimento da adolescente, marcou-se um horário com a paciente, para a realização da entrevista. A pesquisadora colheu as informações que compõem este estudo a partir de entrevista realizada no próprio hospital e ao acompanhá-la em momentos de atendimento individual e grupal, em que também foram feitos registros utilizados na análise de dados.

\section{Inserção Ecológica}

Embora Bronfenbrenner (1999) não tenha chegado a realizar uma proposta metodológica, autoras brasileiras sistematizaram uma metodologia a que denominaram Inserção ecológica (Cecconello \& Koller, 2003), no esforço de adequar os procedimentos de investigação coerentes com a teoria bioecológica. Posteriormente, essa metodologia foi revisada por Prati et al. (2008). Uma obra pioneira reuniu pesquisas de todo o país envolvendo a inserção ecológica (Koller et al., 2016). A inserção ecológica pode ser considerada um método de perspectiva etnográfica embasado pela TBDH e se caracteriza pela inserção da equipe de pesquisa no campo a ser investigado por período de tempo extenso, permitindo a vinculação entre equipe e participantes. A observação participante é o principal meio para originar os registros em diários de campo pelos membros da equipe, de forma a contemplar os elementos do PPCT nas atividades vivenciadas.

Os principais pressupostos da inserção ecológica referem-se ao envolvimento dos pesquisadores no ambiente a ser estudado, o que permite a compreensão do desenvolvimento-em-contexto dos processos proximais presentes. Segundo Tudge (2016), o aspecto mais importante deste método é a explícita participação do pesquisador no sistema, que integra todas as pessoas envolvidas, como pesquisadores, membros da comunidade e participantes do estudo e o próprio contexto. Outra característica relevante, além da sua fidelidade à interpretação do desenvolvimento no contexto à luz da TBDH, é que o microssistema no qual se inserem pesquisadores e pesquisados se constitua em ambiente onde seja possível intenso compartilhamento de suas percepções para a melhor compreensão possível do fenômeno.

A pesquisadora se inseriu em um contexto natural da participante, que, após descobrir a gestação decorrente do incesto, permaneceu durante um ano no serviço de atendimento a vítimas de violência em hospital público. Esse serviço era frequentado pela adolescente com periodicidade semanal. De acordo com Souza et al. (2011), o contexto não precisa existir previamente, podendo ser construído ou proposto como novo microssistema, como foi o caso da adolescente em questão. $O$ hospital não era um microssistema que fazia parte de sua rotina até vivenciar a gravidez decorrente de violência sexual e passar a frequentar o programa de atendimento às vítimas. Neste estudo, será apresentada a análise bioecológica, considerando as falas da gestante no contexto de entrevista e no contexto da ação grupal.

\section{Análise dos Dados}

Para a análise dos dados, foi realizado o procedimento de análise de conteúdo, segundo Bardin (2011), cujas etapas são: a pré-análise, na qual se organiza o corpus de pesquisa; a leitura flutuante de todo o material, na qual se estabelecem os indicadores; e tratamento dos resultados, etapa em que se estabelecem as categorias. Foi utilizada, conforme exposto, a Teoria Bioecológica do Desenvolvimento Humano (TBDH) para articular as vivências da adolescente com os elementos do PPCT, colhidos ao longo do processo de construção das informações. 


\section{RESULTADOS E DISCUSSÃO}

Inicialmente será apresentado um resumo acerca da trajetória de Amanda e sua família até a chegada ao serviço onde se desenvolveu o estudo. A seguir, os resultados serão apresentados à luz das dimensões contexto, pessoa e processo. A dimensão tempo será abordada transversalmente aos eixos anteriores. Serão explicitados trechos literais das transcrições de falas, na tentativa de ilustrar algumas interpretações e de dar voz à participante. O conjunto das interpretações versa sobre uma visão bioecológica da história de vida e de violência, enfatizando a pessoa, o processo, o contexto e a atuação sinérgica desses elementos no desenvolvimento de Amanda.

\section{A História de Amanda e sua Família}

Amanda chegou ao serviço devido à suspeita de gravidez decorrente de abuso sexual intrafamiliar, perpetrado por seu avô materno, que residia com a família. O teste foi realizado e a gravidez, constatada. A intenção da família era utilizar o serviço de interrupção da gestação prevista em lei, porém, pelo fato de a gravidez já ter ultrapassado as vinte semanas gestacionais, não foi possível realizar o procedimento, conforme critério previsto pelo artigo 128 do Código Penal (Brasil, 1940). Após a notícia da inviabilidade da interrupção, a família e a adolescente optaram por ter o bebê e criá-lo.

No entanto, para que seja possível compreender o contexto em que se deu o abuso, sua revelação e todos os acontecimentos posteriores, é necessário conhecer a história dessa família, em especial no que se refere à mãe e ao avô de Amanda. A mãe da adolescente apresenta um passado marcado por sua busca por pertencimento. $\mathrm{O}$ fato de não ter sido criada pelos pais biológicos e doada para a família que a criou fez com que tenha se empenhado muito em buscar suas origens. Ela investiu na procura por seu pai biológico, colocando anúncios em jornais, e assim conseguiu chegar até ele. A partir desse encontro, a mãe de Amanda saiu da cidade onde morava e se mudou com a família para estar próxima de seu pai e irmãos recém localizados. Nessa ocasião, houve uma mudança significativa em sua vida, pois passou a ser filha de seu pai. Diante do divórcio do avô de Amanda, sua mãe, sensibilizada, acolheu-o em sua casa, onde ele passou a morar. Esse alguém, que não poderia afirmar ter desenvolvido laços com ela e com as filhas em tão pouco tempo, elegeu Amanda como depositária de seu desejo sexual e passou a perpetrar abuso sexual contínuo nesse ambiente: "Minha mãe veio conhecer o pai. Minha mãe resolveu morar numa casa só, para recomeçar tudo de novo ... ele [o avô] foi morar junto com a gente...".

\section{Análise Bioecológica dos Sistemas em que Amanda está Inserida e que Impactam seu Desenvolvimento}

Amanda revelou os microssistemas nos quais estava inserida, deixando claro o impacto que a gravidez provocou nesses contextos. Antes da gravidez, Amanda frequentava os microssistemas casa, escola e casa de amigas. Posteriormente à notícia da gestação, passaram a fazer parte de sua rede: a delegacia, o hospital e a casa da amiga da mãe que a acolheu. Rupturas com escola e amigos foram apontadas como formas de evitar que as pessoas soubessem de sua gestação.

O microssistema é um ambiente físico em que a pessoa se insere e interage face a face com outras pessoas e que nele são notadas características dos demais níveis contextuais. (Bronfenbrenner, 1999, 2011). A visão de ambiente experienciado é aqui observada no processo de revelação de Amanda, pois se enfatiza que o ambiente é descrito não pelas propriedades objetivas do meio, mas pela forma como a pessoa percebe e dá significado ao que vivencia no ambiente. Assim, a casa, apesar de ter a rotina estabelecida e papéis aparentemente definidos, foi apontada, na fala de Amanda, como um ambiente inibidor de confissões ou diálogos.

A dificuldade em torno da revelação de uma violência sexual intrafamiliar foi constatada no relato de Amanda e encontra respaldo na literatura (Baía et al., 2015; Tener, 2017). Quem recebe a notícia entra em choque e pode ficar paralisado diante da revelação. No que se refere ao microssistema casa, as mães, nos casos de violência sexual intrafamiliar, geralmente são consideradas não apoiadoras, pois a confiança que depositam no caráter do abusador tende a impedir o reconhecimento dos sinais do abuso sexual em seu próprio lar. Antes da gravidez, Amanda reuniu recursos para a revelação, mas, ao ver suas tentativas frustradas, desistia. O fato de escrever aparece em seu discurso como uma oportunidade de desabafo importante. Porém, conforme Santos et al. (2012), o descaso também pode ser o resultado da revelação, sobretudo se o depositário da revelação não estiver em condições de ajudar. No caso, a mãe de Amanda não foi capaz de encontrar os escritos dela, ainda que em lugares pouco prováveis de não serem encontrados: "Eu lembro que eu nem menstruava ainda ... eu lembro que eu escrevi uma cartinha (choro) falando que ele tinha feito isso comigo e coloquei dentro da bolsa da minha mãe. Você acredita que ela não encontrou?".

A fala de Amanda corroborou os estudos nos quais as mães das filhas que foram violentadas de forma intrafamiliar passam por um descrédito e posterior sofrimento por não se julgarem competentes para proteger (Amazonas et al., 2009; 
Nunes \& Morais, 2018). A revelação do abuso veio com a suspeita da gestação e ela elegeu uma amiga da mãe para romper com um segredo que já guardava há tempos: "Eu não tive coragem de contar diretamente para minha mãe, falei pra colega dela ... ela teve que dar parte do próprio pai dela". Há vários indicadores de relações interpessoais comprometidas no microssistema casa. Amanda reconheceu em seu discurso as fragilidades familiares e se propôs a corrigi-las na criação de sua filha. De acordo com Bronfenbrenner (1999), o coração de um sistema social é a família. Segundo o autor, a família é o mais humano, o mais poderoso e o sistema mais econômico conhecido para tornar e manter o ser humano mais humano. Amanda detectou a falta de comunicação como um dos principais problemas da casa, o que é corroborado pelos estudos sobre características de famílias nas quais está presente o abuso sexual (Santos et al., 2012).

A gravidez, neste caso, demandou rápidas intervenções, o que fez com que o silenciamento fosse quebrado, tanto por quem revelou como por quem ouviu. A mãe de Amanda promoveu o afastamento imediato de seu pai biológico, com a mudança de casa e prisão do perpetrador. Entretanto, acredita-se que a gestação tem um impacto que colabora para essa ação mais efetiva de afastamento.

De acordo com Santos e Dell'Aglio (2013), a revelação do abuso sexual intrafamiliar traz uma série de repercussões também para a mãe da vítima: perdas para si e para a família, conflito entre a lealdade ao ofensor e à vítima, além de implicar o ingresso no sistema de justiça, que, embora possa ajudá-la na proteção, ela teme por desconhecer. No caso de Amanda, houve o agravante da busca incessante que sua mãe empreendeu anteriormente pelo reconhecimento paterno. Esse fator mostrou-se sugestivo de maior dificuldade em lidar com o tema. A mãe de Amanda desejou tanto essa filiação que talvez não tenha percebido a aproximação perigosa do avô.

$\mathrm{O}$ relato de Amanda evidenciou, entretanto, que a gravidez foi capaz de promover mudanças na comunicação familiar, pois a mãe, ao denunciar o próprio pai e apoiar a filha, propiciou uma aproximação e um diálogo até então pouco usual: "Há uma vida, tá dentro de mim, é uma menina ... Eu e minha mãe tivemos pouco diálogo ... Eu quero ser diferente para ela. Ser tudo que a minha mãe não foi em relação a conversar".

Acrise familiar gerada com a revelação pedia providências imediatas. Para isso, diante das dificuldades vivenciadas pela mãe de Amanda, foi importante a ação da rede social presente. No caso, a amiga da mãe e seu esposo viabilizaram o apoio necessário para que a família conseguisse operar. $\mathrm{O}$ ingresso ao programa de assistência às vítimas de violência, pertencente à rede de saúde, foi reconhecido no discurso de Amanda como fator de proteção diante da vulnerabilidade. Houve confiança no serviço oferecido, que, por saber lidar com a questão, transmitiu segurança e uma escuta qualificada isenta de julgamentos. Esta favoreceu a elaboração de sentimentos e a possibilidade de retomada do projeto de vida, abandonado temporariamente pela gravidez.

O mesossistema de Amanda, composto pelo conjunto de microssistemas dos quais participava, apontava a articulação entre casa, hospital e escola: "Antes eu me sentia meio solitária ... todo esse tempo eu tive que aguentar essa situação (...) Agora é terminar isso e recomeçar tudo de novo, voltar a ser aquela menina de antes, na escola, sabe?".

No que se refere ao macrossistema do qual Amanda fazia parte, ressaltam-se as questões de gênero herdadas pelo sistema patriarcal, no qual vigora a construção social dos estereótipos. As construções culturais pautam o discurso do perpetrador e naturalizam a violência nas relações de poder, que a própria sociedade legitima. De acordo com Bandeira (2017), o domínio masculino encontra-se tão internalizado pela cultura que dispensa a figura masculina em si. O avô de Amanda entrou tardiamente em sua vida, mas seu lugar estava reservado pela introjeção emocional que tacitamente o autorizava para o exercício de seu poder simbólico, físico e sexual. Houve uma perversa trama incestuosa, na qual se promoveu uma inversão dos fatos e, propositalmente, dificultou-se o seu entendimento: "Ele dizia, não é coisa ruim, melhor que você estar com qualquer um ...".

\section{A Pessoa Amanda: Forças, Recursos e Demandas em Perspectiva}

Amanda corroborou a teoria de Bronfenbrenner (1999), na qual a pessoa representa um papel ativo em seu processo de desenvolvimento e, de forma dinâmica, transforma e é transformada pelos sistemas nos quais se insere. Conforme nos aponta a TDBH, os atributos da pessoa em desenvolvimento são divididos em três categorias didáticas: as características de força, as características de recurso e as características de demandas.

As características de força são aquelas que impulsionam ou dificultam os processos proximais na forma de comportamentos ativos que os colocam em movimento e podem apresentar-se em dois grupos: forças generativas e forças disruptivas. Amanda apresentou forças generativas bem marcantes, que contribuíram para iniciar e sustentar seus processos proximais: mostrava-se inteligente, articulada, assertiva, aberta e engajada em experiências, mesmo quando as condições adversas estavam presentes indubitavelmente em sua trajetória. Conforme apontam Copetti e Krebs (2004), as características generativas que favorecem o desenvolvimento envolvem orientações ativas, como curiosidade, tendência para empenhar-se em atividades individuais e coletivas, responsividade, capacidade de adiar gratificações e perseguição a uma meta de longo prazo. Amanda apresentou tais características, que podem ser exemplificadas em dois momentos. O primeiro deles quando empreendeu o tratamento terapêutico individual e grupal no serviço de assistência a vítimas de violência, após sua opção, junto à família, por prosseguir com a gravidez, e o 
segundo momento quando assumiu um namoro, mesmo sofrendo efeitos da vivência traumática da violência sexual intrafamiliar.

Amanda revelou ainda recursos de natureza biopsicológica que englobavam experiências, habilidades, conhecimentos e capacidades que podem ter sido utilizados na elaboração dessa difícil situação. Suas pronunciadas habilidades de verbalização e assertividade presentes em seu discurso e atitudes fazem de Amanda uma pessoa que reúne recursos muito profícuos.

As demandas podem ser descritas como atributos pessoais capazes de estimular reações do ambiente social imediato, seja de encorajamento ou rejeição. Amanda, embora se apresentasse tímida em alguns contextos, mostrava potencial para receber atenção e afeto. Apresentava-se sorridente, educada e não despertava sentimentos negativos desencorajadores do ambiente e, como observadora das demandas do ambiente, oferecia-se para colaborar nas situações. Um exemplo foi ter auxiliado a delegacia a prender o perpetrador, acompanhando os policiais ao local de refúgio do acusado. Outro exemplo deu-se nas sessões grupais, nas quais sempre se voluntariava a auxiliar as participantes em qualquer necessidade. Os atributos presentes em Amanda se mostraram muito importantes para desencadear ações progressivamente mais complexas nos processos proximais.

\section{Os Processos Proximais e suas Repercussões: A Gravidez e a Violência Sexual em Tela}

De acordo com Bronfenbrenner (2011), os processos proximais são considerados motores do desenvolvimento. A forma, o poder, o conteúdo e a direção dos processos proximais variam como função articulada de características da pessoa em desenvolvimento, dos contextos nos quais se insere e do tempo histórico em que vive. Vivenciar o período da gravidez e, consequentemente, empreender a construção de um projeto de maternidade representa uma mudança de papel instigadora de desenvolvimento, mesmo em condições adversas. Uma gravidez decorrente de violência sexual promove impactos muito visíveis nos processos e, assim, exigirá o estabelecimento e manutenção de padrões de interações progressivamente mais complexos.

O percurso que Amanda estabeleceu em seu período gestacional mostrou a progressão das interações, ao longo do tempo, e apontou a participação dos contextos na sua ressignificação. Inicialmente ela descreveu seu processo gravídico, ressaltando a rejeição inicial ao bebê, que também foi mencionada pelas demais participantes do grupo. A suspeita e confirmação da gestação geraram em Amanda uma reação típica: posições orbitais que incluíam negação, depressão, revolta e posterior enfrentamento: "Eu queria passar na frente de um ônibus ... para não ter essa criança. Minha mãe sentou comigo e conversou ... eu fiquei tão transtornada, cada dia eu vou superando".
Ao longo do tempo, sobretudo do mesotempo (semanas e meses), houve mudanças nítidas na forma como Amanda percebia sua vinculação com o bebê, mostrando a complexidade crescente de seu envolvimento: "Antes eu nem pensava em amamentar, mas hoje penso diferente... eu tava vendo que minha mãe comprou umas coisas, vou na gaveta, tiro, olho e boto na gaveta de novo...ela (o bebê) já está na minha vida...". Ela própria avaliava seu processo: "primeiro eu não queria, pensei em doar... mas depois eu ia ficando cada vez mais próxima dela".

Amanda temia o futuro. Ela questionava como faria para que sua filha compreendesse a forma como veio ao mundo. A preocupação com a revelação da origem dos filhos é tema recorrente no que se refere à angústia antecipatória que se mostra presente nas mães cuja gestação é decorrente de violência sexual. Amanda declarou que racionalmente entendia ter tempo hábil para trabalhar isso, porém, diante da intenção de oferecer a sua filha uma educação pautada no diálogo, essa dúvida podia gerar paralisia e impotência: "Agora eu não sei como ela vai crescer... E ela vai perguntar: ah, е теи pai?".

Amanda apresentou efeitos de competência do processo proximal ao avaliar as perspectivas positivas que a maternidade poderia lhe trazer. Ela fez menção a um projeto de criação da filha coerente com o que acreditava numa relação filial. Com esta decisão, a experiência de Amanda corroborou os estudos (Lordello \& Costa, 2014; Nunes \& Morais, 2018) sobre a gravidez pós-estupro ser considerada uma mudança que exige da mulher outro papel nas relações interpessoais e que promove o desafio em uma dupla tarefa: ser mãe e manter o cuidado com o filho. De acordo com Xavier e Zanello (2018), é preciso problematizar uma percepção idealizada de maternidade, na qual a mãe sempre deve agir de forma protetiva com relação aos filhos, temendo ser julgada socialmente quando viola essa imagem. Amanda demonstrava preocupação com tais aspectos, questionandose sobre esse novo papel que desempenhará em sua vida, mas adotava postura de disposição para o processo: "Eu não sei como vai ser minha reação quando chegar a ver ela. Acredito que ela vá me trazer ... maturidade ... Não posso simplesmente rejeitá-la".

Outro indicador de efeitos de competência do processo proximal de Amanda esteve relacionado ao seu projeto de vida. Mesmo sem ter clareza do que iria lhe ocorrer, ela incluía, em seu discurso, uma perspectiva pessoal que ia além dos cuidados ao bebê. Em longo prazo, ela pretendia retomar os estudos, profissionalizar-se, empreender relações amorosas, como o namoro da época, e, para o futuro, cogitava formar uma família: " $A i$, eu pretendo estudar muito, não vai me atrapalhar por eu ter uma filha. Em namoro, estou bem realizada ... Agora meu tempo é para o estudo".

$\mathrm{O}$ conteúdo da violência sexual sofrida apresentou notórios efeitos disfuncionais. É importante conhecer esses efeitos, pois os processos proximais de Amanda expressaram a atuação sinérgica do contexto, do tempo e 
das características da pessoa para interromper ou minimizar esses efeitos. Assim, pelas atividades conjuntas que desenvolveu com pessoas, objetos e símbolos, foi capaz de ressignificar sua maternidade e incluir a criação de sua filha em seu projeto de vida.

Entretanto, vários conteúdos da violência em si precisaram ter lugar em seus atendimentos, para que pudesse não reeditá-los em situações futuras. Amanda descreveu a violência a partir de uma progressão nas investidas do perpetrador, que confundia a adolescente quanto à tênue diferenciação entre cuidado e abuso. Na dinâmica da família na qual a violência sexual é presente, é essa roupagem de cuidado que o autor da violência constrói de forma progressiva e perversa, levando a adolescente a duvidar de si mesma (Amazonas et al., 2009; Lima et al., 2019): "Ele me dava coisas que não dava para minha irmã, celular, roupa... eu comecei a sofrer com os abusos, ele dizia para eu não falar nada para ninguém ... não podia conversar com homem, ele não deixava...".

Os argumentos utilizados pelo autor da violência promoveram o pacto de silêncio, solicitando o segredo e a exclusividade da relação. Amanda conseguiu perceber e nominar esse processo, porém se sentiu intimidada pela ameaça e força física. Os agentes coercitivos presentes paralisavam a vítima. A descrição que Amanda fez da violência sofrida corroborou estudos sobre o tema, no que tange à isenção que o abusador faz de sua responsabilidade, apresentando distorções cognitivas, acrescidas da utilização de álcool como fator de associação ao abuso sexual (Lima et al., 2019; Negriff et al., 2015): "Quando ele bebia, ele puxava meu cabelo... partia para agressão para ele não me tocar.. eu já peguei faca, quando ele dormiu para tentar fazer alguma coisa ... eu dormia com meu irmão pra ele não tentar nada". O ciclo recursivo de violência e silenciamento induz a uma situação de sofrimento e aprisionamento que Haliburn (2017) considera como a de uma sobrevivente.

Efeitos disfuncionais típicos da violência sexual englobam baixa autocongruência e autoestima, de forma que as vítimas costumam referir-se a si próprias como não sendo aquilo que gostariam de ser, impactadas pela dominação e humilhação (Assis et al., 2012; Budd \& Bierie, 2018). Amanda retratou, de forma clara, o quanto os abusos sexuais crônicos sofridos foram capazes de transformá-la, assumindo para si um sentimento de menos valia que a imobilizava diante do fato: "Depois que ele começou a fazer tudo isso, eu perdi as forças. Eu me sentia um nada".
A dissimulação como característica presente no perpetrador foi outra violência denunciada por Amanda. Para ela, além da posição submissa e oprimida de vítima com relação às investidas sexuais, havia o sentimento de ódio e rancor despertado pela forma gentil com a qual o autor da violência se apresentava perante as pessoas de sua convivência. $\mathrm{O}$ efeito dessa dissimulação afetou a credibilidade no relato da vítima. As pessoas consideravam o abusador incapaz de cometer qualquer ofensa e, com isso, desacreditavam ou minimizavam as revelações: "era impossivel outra pessoa reconhecer tudo isso que eu passava... quando ele conversava com outras mulheres, incomodava. Não era ciúmes, era raiva que eu sentia ... tudo aquilo era mentira".

Sendo o segredo o princípio organizador dos relacionamentos familiares nos quais está presente a violência sexual intrafamiliar, além da falta de comunicação e de relações de poder bem pronunciadas, é possível compreender a dificuldade de sua mãe em decifrar as mensagens de violência sexual presentes em seu próprio contexto. Amanda, no entanto, entendeu que expressar, contar, é algo que pode promover mudanças e orienta quem pode estar passando por isso: "Vou falar para não se calar, por mais que seja dificil ... vai sentir vergonha, mas é melhor você contar isso antes ... Se eu tivesse contado isso antes eu não estaria assim nessa situação ... eu tô grávida do meu avô". Cabe mencionar o quanto o fato de ter sido finalmente acolhida pela amiga de sua mãe e pela mãe (após saber do fato) contribuíram para sua crença positiva a respeito da revelação e seus desdobramentos.

Os processos de violência continuada são capazes de promover uma ambivalência difícil de compreender para aquele que não está na situação. No caso da violência intrafamiliar, isso é mais impactante pelo fato de haver um vínculo afetivo presente (Dobke et al, 2010; Gomes et al, 2014). Amanda mostrou sinais de admiração e decepção, pena e ódio, credibilidade e dúvida, luta e desistência, afeto e rancor profundo: "Ódio dele. (choro) Era uma pessoa que eu admirava muito... me ensinou muita coisa, mas era só para conseguir tudo que ele queria. ... ele começou a chorar depois do ato dizendo que não queria fazer isso comigo". Amanda apresentava intenso sofrimento ao relatar sua relação com o avô, por não se sentir autorizada a odiá-lo em virtude das múltiplas representações que construiu sobre ele.

\section{CONSIDERAÇÕES FINAIS}

A análise bioecológica permitiu atender aos objetivos do estudo, mostrando o quanto um olhar sistêmico sobre o desenvolvimento humano é capaz de identificar fatores de proteção e potencializá-los. A teoria mostrou como os processos proximais de Amanda foram integrados por uma atuação sinérgica dos contextos, de suas características pessoais e do tempo afetando sua vivência do processo gravídico e da elaboração emocional da violência sofrida, que tantas marcas produziu nela. A leitura de gênero permitiu que fossem observados em sua história os modelos 
patriarcais que difundem estereotipias encontradas na relação que se estabeleceu entre ela e o autor da violência, mantendo o lugar de autoridade deste, a partir do status da dominação masculina legitimada socialmente.

Pesquisas embasadas pela TBDH têm assumido compromisso de prover conhecimentos para a execução de políticas públicas. No caso desse estudo há a pretensão de que os resultados sejam imediatamente incorporados pelo programa de atendimento às vítimas de violência, inserindo conteúdos dessa vivência da gravidez pós-estupro em sua dinâmica de atendimento psicossocial.

A partir de estudos que apresentam o método em diferentes contextos (Koller et al., 2016), é possível concluir que variadas características da Inserção Ecológica puderam ser identificadas no presente estudo. Podem ser aqui mencionados o engajamento em tarefa comum para pesquisador e pesquisado, a regularidade nos encontros, a progressão da complexidade nos conteúdos expressos e trabalhados e processos proximais reconhecidos na pesquisadora e na pessoa pesquisada.

Por outro lado, limitações conceituais e metodológicas foram encontradas, uma vez que a inserção ecológica ainda se mostra uma metodologia em construção e o próprio pesquisador ainda corre o risco de apresentar dúvidas e equívocos, tanto na condução quanto na interpretação das informações obtidas. A limitação do tempo também merece ser observada, uma vez que um processo proximal de tamanha magnitude mereceria um período mais extenso para sua investigação. Nesse sentido, estudos de caráter longitudinal são indicados com vistas a acompanhar o processo da maternidade e os desafios apresentados em seu conteúdo, investigando-se o impacto do projeto de maternidade na criação dos filhos gestados na situação de violência sexual.

\section{REFERÊNCIAS}

Amazonas, M. C., Oliveira, P. A., \& Melo, L. M. M. B. (2009). Repercussions of incestuous sexual abuse on the mother/ daugther. Psicologia em Revista, 15(3), 82-100. http://pepsic. bvsalud.org/scielo.php?script=sci_arttext\&pid=S167711682009000300006\&lng=pt\&tlng=en

Assis, S. G., Avanci, J. Q., Silva, C. M. F. P., \& Oliveira, R. V. C. (2012). Violência na adolescência e formação da autoestima. In L. F. Habigzang \& S. H. Koller (Eds.), Violência contra crianças e adolescentes: Teoria, pesquisa e prática (pp. 8093). Artmed.

Baía, P. A. D., Veloso, M. M. X., Magalhães, C. M., \& Dell'Aglio, D. D. (2013). Caracterização da revelação do abuso sexual: Negação, retratação e fatores associados. Temas em Psicologia, 21(1), 193-202. https://doi.org/10.9788/TP2013.1-14

Baía, P. A. D., Veloso, M. M. X., Habigzang, L. F., Dell’Aglio, D. D., \& Magalhães, C. M. C. (2015). Padrões de revelação e descoberta do abuso sexual de crianças e adolescentes. Revista de Psicologia, 24(1), 1-19. https://doi.org/10.5354/07190581.2015.37007

Bandeira, L. M. (2017). Violência, gênero e poder: Múltiplas faces. In C. Stevens, S. Oliveira, V. Zanello, E. Silva, \& C. Portela (Eds.), Mulheres e violências. Intersecionalidades (pp. 14-35). Technopolitik.

Bardin, L. (2011). Análise de conteúdo. Edições 70.

Brasil. (1940). Decreto Lei no. 2848 de 7 de Dezembro de 1940. http://www.planalto.gov.br/ccivil_03/decreto-lei/del2848.htm

Brasil. (2009). Lei $n^{\circ} 12.015$, de 7 de agosto de 2009. Altera o Título VI da Parte Especial do Decreto-Lei $n^{\circ} 2.848$, de 7 de dezembro de 1940 - Código Penal, e o art. $1^{\circ}$ da Lei $n^{\circ}$ 8.072, de 25 de julho de 1990. http://www.planalto.gov.br/ccivil_03/_ato20072010/2009/lei/112015.htm

Brasil. (2012). Prevenção e tratamento dos agravos resultantes da violência sexual contra mulheres e adolescentes: norma técnica ( $3^{\mathrm{a}}$ ed.). Ministério da Saúde/Secretaria de Atenção à Saúde/Departamento de Ações Programáticas Estratégicas.

Bronfenbrenner, U. (1994). Ecological models of human development. In T. Husen \& T. N. Postlethwaite (Eds.), International encyclopedia of education (2a ed., Vol. 3, pp. 1643-1647). Pergamon Press/Elsevier Science.

Bronfenbrenner, U. (1996). A ecologia do desenvolvimento humano: Experimentos naturais e planejados. Artes Médicas. (Original published in 1979)
Bronfenbrenner, U. (1999). Environments in developmental perspective: Theorical and operational models. In S. L. Friedmann \& T. D. Wacks (Eds.), Measuring environment across the life span: Emerging methods and concepts (pp. 3-30). American Psychological Association.

Bronfenbrenner, U., \& Evans, G. (2000). Developmental science in the 21 st century: Emerging questions, theoretical models, research designs and empirical findings. Social Development, 9, 115-125. https://doi.org/10.1111/1467-9507.00114

Bronfenbrenner (2011). Bioecologia do desenvolvimento humano: Tornando os seres humanos mais humanos. Artmed.

Budd, K. M., \& Bierie, D. M. (2018). Victims of sexual assault perpetrated by female youth: An exploratory study of gender differences. Journal of Sexual Aggression, 24(3), 274-293. https://doi.org/10.1080/13552600.2018.1528793

Cecconello, A. M., \& Koller, S. H. (2003). Inserção ecológica na comunidade: Uma proposta metodológica para o estudo de famílias em situação de risco. Psicologia: Reflexão e Crítica, 16, 515-524. http://www.scielo.br/pdf/\%0D/prc/v16n3/ v16n3a10.pdf

Copetti, F., \& Krebs, R. J. (2004). As propriedades da pessoa na perspectiva do paradigma bioecológico. In S. H. Koller (Ed.), Ecologia do desenvolvimento humano: Pesquisa e intervenção no Brasil (pp. 67-89). Casa do Psicólogo.

Coscioni, V., Nascimento, D. B., Rosa, E. M., \& Koller, S. H. (2018). Pressupostos teórico-metodológicos da Teoria Bioecológica do Desenvolvimento Humano: Uma pesquisa com adolescentes em medida socioeducativa. Psicologia USP, 29(3), 363-373. https:/doi.org/10.1590/0103-656420170115

Diniz, D., Dios, V. C., Mastrella, M., \& Madeiro. A. P. (2014). A verdade do estupro nos serviços de aborto legal no Brasil. Revista Bioética, 22(2), 291-298. https://doi.org/10.1590/198380422014222010

Dobke, V. M., Santos, S. S., \& Dell'Aglio, D. D. (2010). Abuso sexual intrafamiliar: Da notificação ao depoimento no contexto processual-penal. Temas em Psicologia, 18(1), 167-176. https:// www.redalyc.org/articulo.oa?id $=513751435014$

Gomes, V., Jardim, P., Taveira, F., Dinis-Oliveira, R. J., \& Magalhães, T. (2014). Alleged biological father incest: A forensic approach. Journal of Forensic Sciences, 59, 255-259. https://doi.org/10.1111/1556-4029.12310 
Haliburn, J. (2017). Mother-child Incest, Psychosis, and the Dynamics of Relatedness. Journal of Trauma \& Dissociation, 18(3), 409-426. https://doi.org/10.1080/15299732.2017.12 95424

Hartchard, C. J., Goodwin, J. L., Sidall, E., \& Muniz, L. (2017). Perceptions of abusive parenting behaviors: A preliminary exploration into the underrecognition of mother-daughter sexual abuse. Journal of Child Sexual Abuse, 26(4), 428-441. https://doi.org/10.1080/10538712.2017.1300971

Hohendorff, J. V., Habigzang, L. F., \& Koller, S. H. (2015). Psicoterapia para crianças e adolescentes vítimas de violência sexual no sistema público: Panorama e alternativas de atendimento. Psicologia: Ciência e Profissão, 35(1), 182198. https://doi.org/10.1590/1982-3703000202014

Koller, S. H., Morais, N., \& Paludo, S. S. (2016). Inserção ecológica: Um método de estudo do desenvolvimento humano. Casa do Psicólogo.

Lima, C. A., \& Deslandes, S.F. (2014). Violência sexual contra mulheres no Brasil: Conquistas e desafios do setor saúde na década de 2000. Saúde e Sociedade, 23(3), 787-800. https:// doi.org/10.1590/S0104-12902014000300005

Lima, M. C., D., Larocca, L. M., \& Nascimento, D. J. (2019). Abortamento legal após estupro: Histórias reais, diálogos necessários. Saúde Debate, 43(121), 417-428. https://doi. org/10.1590/0103-1104201912110

Lordello, S. R., \& Costa, L. F. (2014). Gestação decorrente de violência sexual: Um estudo de caso à luz do Modelo Bioecológico. Contextos Clínicos, 7(1), 94-104. https://doi. org/10.4013/ctc.2014.71.09

Lordello, S. R., \& Lopes de Oliveira, M. C. S. (2012). Contribuições conceituais e metodológicas do modelo bioecológico para a compreensão do abuso sexual intrafamiliar. Psico, 43(2), 260-269. https://dialnet.unirioja.es/servlet/ articulo? codigo $=5633161$

Morais, C. A., Borba, A., \& Koller, S. H. (2016). O uso do diário de campo no processo de inserção ecológica. In S. H. Koller, N. A. Morais, \& S. S. Paludo. (Eds.), Inserção ecológica: Um método de estudo do desenvolvimento humano (pp. 299-319). Casa do Psicólogo.

Negriff, S., Schneiderman, J. U., \& Trickett, P. K. (2015). Child maltreatment and sexual risk behavior: Maltreatment types and gender differences. Journal of Development \& Behavior Pediatrics, 36(9), 708-716. http://doi.org/10.1097/ DBP.0000000000000204

Nunes, M. C. A., \& Morais, N. A. (2018). Gravidez pós-estupro: Considerações com base na Abordagem Bioecológica do Desenvolvimento Humano. Contextos Clínicos, 11(3), 286296. http://doi.org/10.4013/ctc.2018.113.01
Pflugradt, D. M., Allen, B. P., \& Marshall, W. L. (2018). A gendered strength-based treatment model for female sexual offenders. Aggression and Violent Behavior, 40, 12-18. https://doi. org/10.1016/j.avb.2018.02.012

Prati, L. E., Couto, M. C. P. P., Moura, A., Poletto, M., \& Koller, S. H. (2008). Revisando a Inserção Ecológica: Uma proposta de sistematização. Psicologia: Reflexão e Crítica, 21(1), 160-169. http://doi.org/10.1590/S0102-79722008000100020

Rakovic-Felser, Z., \& Vidovic, L. (2016). Maternal perceptions of and responses to child sexual abuse. Zdrav Var, 55(2), 124-130. https://doi.org/10.1515/sjph-2016-0017

Rosa, E. M., \& Tudge, J. (2017). Teoria Bioecológica do Desenvolvimento Humano: Considerações metodológicas. In A. C. G. Dias \& E. M. Rosa (Eds.), Metodologias de pesquisa e intervenção com crianças, adolescentes e jovens (pp. 17-43). Edufes.

Santos, S. S., \& Dell'Aglio D. D. (2013). O processo de revelação do abuso sexual na percepção de mães. Psicologia Teoria e Prática, 15(1), 50-64. https://www.redalyc.org/ pdf/1938/193826310015.pdf

Santos, S. S., Pelisoli, C., \& Dell'Aglio, D. D. (2012). Desvendando segredos: Padrões e dinâmicas familiares no abuso sexual infantil. In L. F. Habigzang \& S. H. Koller (Eds.), Violência contra crianças e adolescentes: Teoria, pesquisa e prática (pp. 55-68). Artmed.

Scoones, C. D., Willis, G. M., \& Grace, R. C. (2012). Beyond static and dynamic risk factors: The incremental validity of release planning for predicting sex offender recidivism. Journal of Interpersonal Violence, 27, 222-238. https://doi. org/10.1177/0886260511416472

Souza, A. P. L., Dutra-Thomé, L., Dei Schiró, E. D. B. D., Morais, C. A., \& Koller, S. H. (2011). Criando contextos ecológicos de desenvolvimento e direitos humanos para adolescentes. Paidéia, 21(49), 273-278. https://doi.org/10.1590/S0103863X2011000200015

Stake, R. E. (1995). The art of the case study research. Sage Publications.

Tener, D. (2017). The secret of intrafamilial child sexual abuse: Who keeps it and how? Journal of Child Sexual Abuse, 27, 1-21. https://doi.org/10.1080/10538712.2017.1390715

Tudge, J. (2016). Prefácio. In S. H. Koller, N. A. Morais, \& S. S. Paludo (Eds.), Inserção ecológica: Um método de estudo do desenvolvimento humano (pp. 7-14). Casa do Psicólogo.

Xavier, A., \& Zanello, V. (2018). Ouvindo o inaudito: Mal estar da maternidade em mães ofensoras atendidas em um CREAS. Revista de Ciências Humanas, 52, e57051. https://doi. org/10.5007/2178-4582.2018.57051 